\title{
Formulation and development of a granola bar with rice flakes and vegetables
}

\author{
By \\ Theekshani Sankalpana Liyanage
}

This Thesis submitted in partial fulfillment of the requirements for the Degree of Masters of Food Science and Technology,

Department of Food Science and Technology,

Faculty of Applied Science,

University of Sri Jayewardenepura, Sri Lanka

M.Sc.

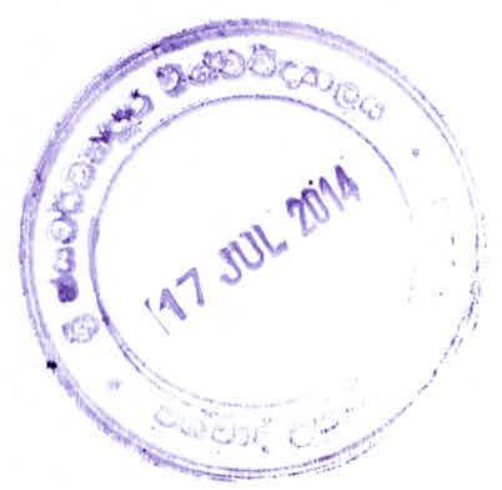




\section{DECLARATION}

The work described in this thesis was carried by me, under the supervision ofProf.ArthurBamunuarachchi and the report on this thesis has not been submitted in whole or in part of any University or any other institution for another Degree/ Diploma.

$28 / 3 / 2014$

Date 7.5hjar

T. Sankalpana Liyanage 


\section{Declaration of the supervisor}

I, Prof. Arthur Bamunuarachchi certify that the above statement made by the candidate is true and this thesis is suitable for submission to the University for the purpose of evolution.

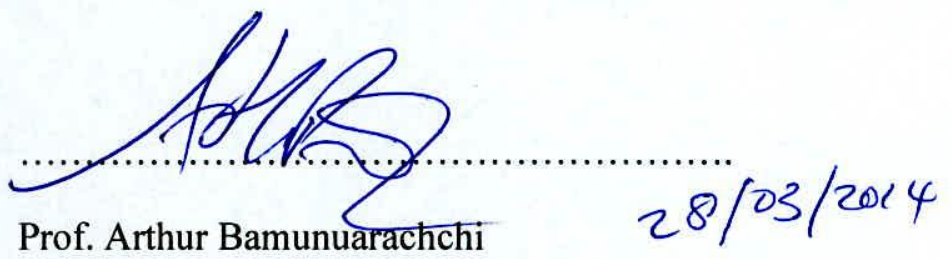

Department of Food Science and Technology,

Faculty of Applied Sciences,

University of Sri Jayewardenepura,

Sri Lanka. 


\section{Table of content}

Table of contents $\quad$ i

List of table vi vi

List of figures $\quad$ vii

Acknowledgement viii

Abstract $\quad$ ix

1.0 Introduction

1.1 Introduction 1

1.2 Objectives 3

2.0 Review of Literature

2.1. Food bar 4

2.1.1. Energy bars 4

2.1.2. Cereal \& Granola Bars $\quad 4$

2.1.3. Market trend 4

2.2. Important Characteristics of rice 5

2.2.1. Scientific classification of the rice 5

2.2.2. Rice flakes 6

2.2.3. Nutritional facts $\quad 7$

2.2.4. Health benefits of brown rice flakes $\quad 8$

2.3. Important Characteristics of Carrot 11

2.3.1. Scientific classification of the Carrot 11

2.3.2. Health Benefits 12

2.3.3. Nutritional facts of carrot $\quad 15$

2.4. Characteristics of curry leave 16

2.4.1. Scientific classification $\quad 16$

2.4.2. Health benefits 18

2.4.3. Nutritional facts of curry leave 20

2.5. Information of Dried plums 21 
2.5.2. Health benefits of dried plums 23

2.5.3. Nutritional information of prunes 26

2.6. Characteristics of peanuts 27

2.6.1. Scientific classification of the peanuts 27

2.6.2. Health benefits of peanuts 27

2.6.3. Nutrition content $\quad 29$

2.7. Bee honey 30

2.7.1. Health benefits 31

2.7.2. Nutritional value $\quad 32$

2.8. Pumpkin seeds 33

2.8.1. Nutritional value 33

2.8.2. Health benefits $\quad 34$

2.9. Chocolate chips $\quad 35$

2.9.1. Nutrition Facts 36

2.10. Granola bar recipes 36

2.10.1. Granola bar recipe, made with rice flakes 36

2.10.2. Chewy Pumpkin Spice Granola Bars 37

2.10.3.Carrot Cake Energy Squares 38

3. Material and methodology $\quad 39$

3.1. Materials for making granola bars $\quad 39$

3.2. Preparing ingredients for making granola bars 40

$\begin{array}{ll}\text { 3.2.1 Making dried carrots and curry leaves } & 40\end{array}$

3.2.2. Making other ingredients of the granola bar 41

3.3. Preparation of granola bar with suitable vegetable bounding 41

3.3.1. Methodology 41

3.4. Sensory evolution $\quad 42$

3.5. The flow chart of making cereal bar with carrot paste 43 
3.5.4. The flow chart

3.6. Proximate analysis

3.6.1. Determining Moisture-Oven dry method

3.6.1.1. Materials

3.6.1.2. Methodology

3.6.2. Determination of total fat

3.6.2.1. Apparatus

3.6.2.2Chemicals

3.6.2.3. Methodology

3.6.3 Determination of crude protein

3.6.3.1. Material

3.6.3.2. Methodology

3.6.4. Determination of crude fiber content

3.6.4.1. Apparatus

3.6.4.2. Chemicals

3.6.4.3. Methodology

3.6.5. Determination of total ash

3.6.5.1. Materials

3.6.5.2. Methodology 
3.7.1.1. Material

3.7.1.2. Dilution procedure

3.7.2. Aerobic plate count (APC)

3.7.2.2. Medium: Standard Plate Count Agar (SPCA)

3.7.2.3. Plating

3.7.4. Most Probable Number (MPN) method

3.7.4.1. Materials

3.7.4.2. Methodology

3.8. Shelf life determination

3.8.1. Determination of Peroxide value

3.8.1. Materials

3.8.2. Chemicals

3.8.3. Methodology

4.1.1. The preparation of the granola bar with rice flakes with vegetables

4.1.2. The ingredients

4.2. Sensory analysis for the selection of best cereal bar formula

4.2.1.1The color

4.2.1.2The smell 
$\begin{array}{ll}\text { 4.2.1.5The taste } & 61\end{array}$

$\begin{array}{ll}4.2 .1 .6 O v e r a l l ~ a c c e p t a b i l i t y & 61\end{array}$

4.3. Proximate composition of the granola bar 62

4.4. The shelf life evaluation 62

$\begin{array}{ll}\text { 4.5. Microbial assessment } & 62\end{array}$

4.6.1. Sensory analysis for the determination of the preference for the formulated food sample to commercial products

\section{References}

Appendix 


\section{List of tables-}

$\begin{array}{ll}\text { Table 1-Nutritional facts of rice flakes } & 7\end{array}$

$\begin{array}{lr}\text { Table 2- Nutritional facts of carrot } & 15\end{array}$

$\begin{array}{ll}\text { Table 3- Nutritional facts of curry leave } & 20\end{array}$

Table 4- Nutritional information of prunes $\quad 26$

Table 5- Nutrition content of peanuts $\quad 29$

Table 6 - Nutritional content of bee honey 32

Table 7-Nutritional content of pumpkin seeds 33

Table 8-Summarize the estimated mean of the samples 243,245,247,249 59

Table 9 -the summarize the median of the samples243, 245,247,249 59

Table 10- proximate composition of selected granola bar recipe 62

Table 11 -Summarize the estimated mean of the sensory attributes of the sample and commercialproducts $543,545,547$

Table 12 -the summarize the median of the sensory attributes of the sample and commercialproducts $543,545,549$ 


\section{List of graphs-}

1. Graph-The graph which shows the mean values of the attributes of the samples 60

2. Graph- The graph which shows the mean values of the attributes of the samples 64

\section{List of flow charts-}

3.2.1. Flow chart 1-Making dried carrots, curry leaves 40

3.5. Flow chart 2-The flow chart of making cereal bar with carrot paste 43

\section{List of pictures}

Picture 1- The picture of dried carrots $\quad 41$

Picture 2-the picture of the rice flakes after frying 43

Picture 3-The picture of carrot when making carrot paste $\quad 44$

Picture 5 -The pictures of Chocolate chips, Pea nut, pumpkin seeds 44

Picture 6-The picture of the bowl shows granola bar mixture after adding all ingredients 45

Picture 7-The picture shows granola layer after heating in the oven 46

Picture 8-The picture shows the layer after decorating with chocolate. 46

$\begin{array}{ll}\text { Picture 9-Picture of the cereal bars } & 47\end{array}$ 


\section{Acknowledgment}

First of all I would like to express my heartfelt gratitude to my project supervisor Prof. ArthurBamunuarachchi, for his valuable advises and guidance throughout the study.

I offer my sincere thanks to Dr. JagathWansapala, Prof.K.K.D.S. Ranaweera, Dr. S.D.

Navarathna, Mrs.RupikaPerera, for giving me valuable assistance throughout the study.

I also would like to thank everyone in the Food Science laboratory at the University of SriJayawardanepura who helped me in various ways to conduct my research

Finally I like to offer my thanks to my brother for encourage me to complete this project. 


\begin{abstract}
Granola bars are supplemental bars containing cereals and other high energy foods targeted at people that require quick energy, and for people who want to reduce their body weight. Granola bars have become a popular meal replacement for active people and serve as a healthy snack for people looking to add a few extra calories. The present cereal bar is made up with rice flakes, carrots, curry leaves, dried plums, peanuts, pumpkin seeds and chocolate. These ingredients provide excellent source of carbohydrate, protein, fat, vitamins and minerals. This food product is suitable for children, adults and pregnant mothers. By consuming this product, one's health condition can be enhanced up to higher level. This product can be utilized as a supplement for a meal or a food supplement between two meals.

The objective of the study was to formulate a nutritious and economical energy bar using cereal, vegetable, and fruits using a traditional food base. Granola bar samples were evaluated organoleptically by a group of panelists using a statistical analysis in order to find the best formula. The selected best formula was adjusted by adding some food flavors. The best food formula was finalized by sensory evaluation and statistical analysis.

Proximate analysis was conducted to determine the nutritional composition of the granola bar. After preparation of the granola bar was packed and kept at room condition. The selected cereal bar was subjected to peroxide test at every week and the microbiological test was carried out at every two weeks.

Having followed the above process, better consumer acceptable granola bar with rice flakes and vegetable could be formed. That granola bar has $4.363 \%$ moisture content, $68.8316 \%$ carbohydrate content, $16.5097 \%$ total fat content, $3.4341 \%$ protein content, $2.1051 \%$ crude fiber content, and $4.7565 \%$ ash content. The energy of granola bar was $437.6501 \mathrm{kcal} / 100 \mathrm{~g}$. The maximum shelf life of the product was up to 3 months under room conditions. The product was microbiologically safe and there wasn't any observation of Coliform bacteria presence in the sample.
\end{abstract}

Further studies should be carried out for improve all the aspects of the finally developed granola bar. 


\subsection{Introduction}

Food bar is a fast food, considered as an "on the go snack". It is a delicious snack and also a nutrition supplement, suitable for all ages. Food bar is a simple solution for the people who are seeking healthy food to boost up the energy that require for daily work, to minimize the hungry feeling in a busy life style and to help people to maintain the physical wellbeing with a balanced diet.

In Sri Lanka the consumption of fast food and snacks has been increased significantly in recent years, revealing a trend of change in lifestyles. People don't have enough time to sit and take regular meals, they simply take fast food. That opens the market forpurchasingof ready to eat and pre-prepared food. Thosefood items contain high amount unsaturated oil, cholesterol, fat, high sugar, high amount of Sodium Chloride which highly affect to human health, and those are considered as unbalanced foods (junk food). These do not contain required amount of minerals, vitamins. Thus, most adults are suffering from the cardio vascular diseases and diabetic. Today even teenagers are suffering from diabetics because of taking unhealthy, unbalancing foods.

Food bars have better nutritional values than other fast foods and bakery products like buns, cakes, pastries, rolls, items which are considered as junk food. Further those are engagedin sports like hiking mountains, as they are not too messy and occupy minimum space. Owing the growing consumer demand for healthy, natural and convenient food, attempts are being made to improve snack nutritional values via modifying their nutritive composition. Granola bars supply carbohydrates, protein, fat, vitamins, minerals etc. It is considered as a healthy food.Food bars have advantages such as, being very convenient, fit into a briefcase, purse or pocket of working people, children or anyone and making them easily to take with individuals anywhere and to eat anytime.

Having a product that keeps consumer satiated, consumers are able to decrease food intake without enduring high levels of hunger between meals by taking any junk food. In fact, granola bars do produce greater reductions in hunger and greater increases in fullness than conventional low-calorie food. The purpose of an energy bar is to reduce fatigue and improve concentration at vital times. 
Granola bar is a cereal bar which contains cereals and multi-grains. Energy bar does not belong to the confectionery segment (chocolates) but belongs to an emerging category called functional food, contains health promoting ingredients. These products are known as nutriceauticals.

The commercially available snacks are generally highly unhealthy. They are energy dense but do not provide nutrients vital to health.

These products are energy rich materials, fortified with a high fiber, complex carbohydrate protein, vitamins and minerals and very low fat minerals as well, making them a healthier choice than a fast food option or a convenient store meal. When the fat content is considered, they have fat without high cholesterol level and saturated fat.

Truly effective food bars should provide fast-acting carbohydrates to facilitate ultra-quick energy delivery. They also need a generous glucose content to help to ensure that a body is properly fuelled when it needs it most.

Food bar is effective in weight loss, fat loss and overall body composition and dimension improvements, as well as satiety (feeling of fullness) and taste acceptability. Food bar is a safe and effective method of weight loss because it keeps feeling satisfied, reducing unhealthy food intake between meals. Granola bar produces greater reductions in hunger and greater increases in fullness than conventional low-calorie food.

Food bars help consumer to eat right and to achieve and maintain a healthy body weight. By incorporating a sensible diet with moderate exercise, consumer too can achieve a healthier lifestyle.

The greatest difficulty in obtaining a good cereal bar is the combination of several ingredients with specific functionality such as vitamins, minerals, proteins, grains, fibers, thickening agents, sweeteners and flavorings, and turns them into a product with flavor, texture and decent appearance, while it tries to achieve specific nutrient goals.

In this research, the granola bar was formulated and developed using locally available raw materials and also with vegetables with favorable consumer acceptance and also that research is carried out to make high nutritional granola bar. To select the best formulation of a product 
sensory analyzing process was used, which is based on fundamental psychological perception and physiological techniques.Hedonic scales are used by untrained consumers to select best formula of food bar. Proximate analysis was used to determine the carbohydrate, protein, fat, fiber, moisture percentage, ash content. Finally product shelf life was measured. The experimental works of the research were carried out at the laboratory of University of Sri Jayawardanapura.

\subsection{Objectives}

\section{Overall objective}

To formulate nutritious and economical granola bar using cereal, fruits, vegetables and traditional foods as based food product.

\section{Specific objectives}

1. Develop an energy bar with cereal and vegetable, by combining them in different ratios

2. Select the best formulas by conducting sensory analysis.

3. Analyze nutritional composition of selected best formula.

4. Analyze the microbiological quality of the product.

5. Determine the shelf life of the product. 